\title{
The Image of Brazil as a Tourism Destination: An Exploratory Study of the American Market
}

\author{
Fabiana Gondim Mariutti \\ Master of Science in Organizations Management, Faculty of Economics \\ Management and Accounting of Ribeirão Preto (FEA-RP), University of São Paulo (USP) \\ Av. Bandeirantes 3900, Monte Alegre, Ribeirão Preto (SP), CEP: 14040-905, Brazil \\ E-mail: famariutti@yahoo.com.br
}

Janaina de Moura Engracia Giraldi (Corresponding author)

Tenured Professor, Faculty of Economics, Management and Accounting of RibeirãoPreto (FEA-RP)

University of São Paulo (USP), Av. Bandeirantes 3900, Monte Alegre, Ribeirão Preto (SP), CEP: 14040-905, Brazil

Tel: 55-16-3602-3903E-mail: jgiraldi@usp.br

Edson Crescitelli

Tenured Professor, Faculty of Economics, Management and Accounting (FEA), University of São Paulo (USP)

Av. Prof. Luciano Gualberto, 908. Butantã, São Paulo (SP), CEP: 05.508-900, Brazil

Tel: 55-11-3818-4038Ｅ-mail: edsonc@usp.br

Received: August 28, $2012 \quad$ Accepted: September 27, $2012 \quad$ Online Published: January 5, 2013

doi:10.5430/ijba.v4n1p13 URL: http://dx.doi.org/10.5430/ijba.v4n1p13

This study has received financial support from the São Paulo Research Foundation (Fapesp) and from the National Council for Scientific and Technological Development (CNPq).

\begin{abstract}
The aim of this paper is to evaluate the image of Brazil as a tourism destination as perceived by travel agents and tourism experts in the United States. The research was qualitative and exploratory, consisting of a literature review followed by an empirical investigation using in-depth interviews with travel agents and tourism experts located in the cities of New York, Miami, Orlando, and Atlanta. The findings reveal that images of Brazil have been converging in terms of diversity and ambiguity. It is important to review the negative and positive aspects cited in this study to minimize the negative elements and highlight the positive or attractive elements.
\end{abstract}

Keywords: Destination image, Destination branding, Country image, Brazil

\section{Introduction}

"Almost every place on Earth gets the image it deserves", says Anholt (2007, p.35). This philosophy can be strategically considered within a global environment that is linked geographically and economically through modern communication technologies. Brazil is one of a few emerging countries that enjoys an international image of a strong country with a vigorous and growing economy, it has a government that encourages exports, it has extensive experience developing successful domestic brands, and it is known for having the most active and creative advertising agencies in the world (Anholt, 2000). Such a reputation has been positive for the country, which needs to strengthen its image in target markets to increase the inflow of tourists and investments to the country.

Tourism has been viewed in the past as a private sector business (Gee \& Fayos-Sola, 2003) and as representing a set of diversified services that generate profit or produce goods and services for tourists. Currently, governments including 
Brazil recognize the important role of tourism in the development of the national economy because of the positive impact tourism can have on generating employment and tax revenue.

According to data from the World Tourism Organization (WTO), in 2011, the international tourism industry generated U.S. $\$ 6$ trillion in revenues for the global economy and 260 million jobs worldwide. The number of international tourists grew from 435 million to 675 million in 2000 and 940 million in 2010 (World Tourism Organization, 2012). According to WTO forecasts, in 2012, the number of international tourists worldwide will increase from 940 million to 1 billion, and there will be greater flows of tourists to emerging economies, with a reduction in the percentage of visits to European destinations from $51 \%$ to $41 \%$ (WTO, 2012).

However, Brazil represents an insignificant number of such international tourists. The country receives approximately 5 million foreign visitors annually, compared with approximately 80 million in France, 70 million in Spain, and 50 million each in the U.S. and Italy (Cioffi, 2011). In the face of this phenomenon enabled by globalization, tourism plays an important role in social, cultural, and economic development for countries as well as the world by generating investments, profitability, and direct and indirect jobs. According to the WTO (2012), the tourism industry contributed 2826000 direct jobs (2.9\% of the total employment) to Brazil in 2011, with an expected increase of $2.3 \%$ of total employment, equivalent to 3564000 direct jobs, by 2021 . The total contribution by the tourism industry, including indirect jobs, is expected to increase from 8154000 jobs (8.3\% of total employment) in 2011 to 9747000 jobs in 2021 $(8.9 \%)$.

In addition to these data, and in view of upcoming world-class sporting events in Brazil, the Brazilian Ministry of Tourism has undertaken projects for investment and infrastructure improvements. However, for these projects to be a positive opportunity, it is worth rethinking the consideration of Anholt (2007) that to take charge as the host country of an important international sporting event without proper long-term planning for capitalizing on the impact on the image of the country is to govern incompetently, with direct implications for the international reputation of the country.

Public policy initiatives, when aligned with private entrepreneurship, can directly and indirectly generate more options for tourism development and related services. After thirty years of development, Brazilian tourism reached high levels of operational quality and planning, but there are still many points that need to be improved. Public policy is one area that needs to be strengthened (Beni, 2006). Being planned, structured, and prepared well may offer a unique opportunity for Brazil to gain international exposure and for the city of Rio de Janeiro to become a recognized world capital in tourism, as occurred with Barcelona after the 1992 Olympics.

In this promising context, Brazil has the potential to expand its presence significantly in the international tourism scene by developing its image and positioning itself in the market to promote domestic tourism businesses and economic development. Thus, we discuss this subject at a pertinent moment, whether in terms of politics, economics, business, or diplomatic relations.

It is worth noting that a country's international reputation is enhanced by aligning innovation with strategy (Anholt, 2007). Thus, the relationship between the shaping of innovative strategies and a country's positioning in the international tourism market is associated with brand strategy. Through an understanding and knowledge of image management, government planning and management of public policies should occur to ensure that innovation is more focused and appropriate to the needs and resources of the country (Anholt, 2007), making understanding a country's image a possible approach to advancing in the international tourist market.

The objective of this paper is to evaluate the image of Brazil as a tourism destination among travel agents and tourism experts in the United States. For this approach, we have developed an exploratory and qualitative study, based on a literature review of relevant topics and complemented by empirical research that consisted of in-depth interviews with travel agents in the cities of New York, Miami, Orlando, and Atlanta.

The following sections present the theoretical foundation for the study (tourism destination image and brand, the image of Brazil as a tourism destination), followed by a description of methodological procedures, a summary of the results, and final considerations.

\section{Tourism Destination Image and Brand}

According to Nadeau, Heslop, O'Reilly and Luk (2008), tourism is a way for people to expose themselves to other countries and to contribute to the images formed about the countries. Given the increasing number of tourism destinations resulting from competition in the global tourism market, one potential strategy is customizing the development of destination brands and creating a unique identity for local tourism (Ekinci \& Hosany, 2006). 
Although a tourism destination is defined as a region where tourists choose to travel outside of their place of residence, the definition of the destination image is a concept that has changed since the 1970s, when the impressions of a place that actual or potential tourists could have were synthesized. Currently, tourists preview the experiences they will have at the destination and, through positive emotions, select a destination based on the most favorable ideas (Pérez-Nebra \& Torres, 2010; Tapachai \& Waryszak, 2000).

Recently, in examining the role of favorable images in the selection of a destination, it appears that tourists have difficulty in obtaining objective measures of the attributes of the intended destination, which positions the destination image within the process of holistically assessing a particular tourism product (Tapachai \& Waryszak, 2000). In other words, a destination is evaluated positively or negatively in a comprehensive manner that is separate from the particular attributes associated with that tourism destination (e.g., accommodations, transportation, or food).

A tourism destination may be positively imagined before the trip or chosen according to a cost-benefit calculus. However, in the face of a scarce amount of searchable information and limited knowledge, there can be discrepancies in the imagined and actual tourism experience. For example, Anholt (2007) shows that places such as the United States or Rio de Janeiro can be considered to be famous by most of the world's population, but being famous is not necessarily a positive attribute (Anholt, 2007), as is the case presently in Iran and North Korea, which are more accurately considered to be infamous. The question being evaluated in this article is how, in the case of Brazil, destinations with famous images are viewed negatively.

Data regarding the country visited appear to aid in the evaluation of the target image, but aspects of the environment especially shape the tourism experience. Based on how people and the country are perceived, there is an impact on the assessments formed regarding the destination and an influence on the tourism industry (Nadeau et al., 2008) relating to the logic of perception in the country of origin influencing tourists' experiences with tourism services. Strengthening this premise, the traditions and culture of a people represent the set of values that provide a nation with its social identity (Oliveira \& Martins, 2009).

Baloglu and Mccleary (1999) presented a paper on the influence of the image in choosing a holiday destination and claimed that strategic image management is important for creating and implementing marketing programs that enhance images of tourism destinations. The relationship between the destination's image and one's intention or preference for visiting that destination demonstrates that the image is a valuable concept for understanding the process of destination selection. In promoting and disseminating a destination through its image, both the attributes of destination and the motivation of the tourists should be considered. According to Morgan, Pritchard, and Pride (2010), currently, the choice of holiday destination has become a significant identifier of lifestyle, and the site chosen for a brief vacation must be emotionally fascinating.

In a literature review on the analysis of the destination image, Pike (2002) confirmed that almost three decades after the first studies were performed in 1973, the topic had become one of the most popular in the area of tourism research. Therefore, there is a need for applied research on destinations to leverage a favorable image of a country (Pike, 2002). Simultaneously, according to Qu, Kim and $\operatorname{Im}$ (2011, p.467), "the image itself is the beginning point of tourist's expectation". Given that, this empirical investigation can enlighten Brazil's image abroad in a deeper way.

According to Tapachai and Waryszak (2000), when considering research on destination image over the last four decades, "Most studies have focused on attributes of the destination image, but do not refer to the image characteristics of the destination that affect decisions to visit specific locations", suggesting how future studies may fill this academic gap. Thus, we believe that this paper can contribute to formulating communication actions for the attraction to and selection of tourism destinations in Brazil in the international market.

Whereas the image of a country is presented as a dimension that guides consumer behavior by providing information about the country for the decision-making process, the destination image also refers to the perception of the destination itself (Nadeau et al., 2008). Such perceptions may be categorized as follows: natural environment, climate, culture, friendliness, relaxation, entertainment, satisfaction, service quality, and general assessment (Gallarza, Saura \& Garcia, 2002).

Because tourism exhibits peculiarities such as intangibility and inseparability and because a tourist's decision to make a purchase to visit a destination is based on a mental construction of places and on the set of attributes formed from beliefs, ideas, and impressions, the study of image becomes central to strategic destination management. Thus, the destination image is considered to be a key variable in the selection process (Machado, Medeiros \& Goslingal., 2010).

From a different and more comprehensive perspective, Pike (2008) believes that the majority of tourist products are services rather than goods and therefore that they can often compete only through images because the destination has 
multiple attributes. The competitiveness of a destination in the international tourism market depends on a balance among various attributes: the presence of tourism companies, effective market position, attractive physical environment, positive tourist experiences, and support from local residents (Pike, 2008). Pike also considers the additional dimensions relevant for marketers: intangibility and risk, variability and inseparability, perishability, and substitutability (Pike, 2008).

On the issue of intangibility, which is also a characteristic of services, physical evidence of a destination is available only through catalogs, websites, photographs, or the media (Pike, 2008). Thus, the implication of intangibility is greater risk during the tourist's decision making. With regard to variability and inseparability, Pike (2008) illustrates that consumers are actively involved in service delivery because production and consumption occur simultaneously. In terms of perishability, destinations do not maintain periods of high demand because of seasonality, periodicity, special events, or disasters (Pike, 2008). Finally, substitutability is represented by the myriad of destinations available in the competitive tourism market that can be replaced by others that meet similar needs (Pike, 2008). To evaluate the destination image, the various dimensions defined differently by various authors are presented in Table 1 .

As discussed by Pike (2008), the complexity of managing a destination brand arises from six factors as applied to the theory of branding for a tourism destination. First, destinations are more multidimensional than consumer goods and other services (Morgan et al., 2010; Pike, 2008). To reach the minds of consumers, there must be a brief message with a focus on one or a few brand associations. In the second factor, the market interests of a diverse group of active stakeholders are heterogeneous, raising the question of how to achieve a variety of geographic markets to attract a wide range of segments given a variety of products (Pike, 2008).

The third factor is related to decisions about branding and how those responsible for actions are indicated. Policy can appear to be at odds with organizations responsible for the promotion of tourist destinations. In the fourth factor, there is a delicate balance to be struck between public consensus and brand theory because a top-down approach to implementing a destination brand is likely to fail. The fifth factor, brand loyalty, is measured and monitored based on repeat visits. Finally, the sixth factor is financing, a continuous problem for organizations in terms of managing scale and consistency, which generally depends on lobbying for public and private investment (Pike, 2008).

Pike (2008) presents three interrelated concepts for the development of a tourism destination brand (whether for a country, a state, or a city): brand identity, brand positioning, and brand image. The brand identity is an internal focus (issues such as self-image and vision of the stakeholders), whereas the brand image refers to the current image held in the market. Finally, the brand positioning represents the potential that interacts with the concepts of brand identity and brand image. As established by Qu et al. (2011, p.467), the concept for "positive brand image is achievable through emphasizing strong, favorable, and unique brand associations".

The relevance of this subject is noted by Beni (2006), who noticed that although destination marketing is the main component of tourism management, the role of brand marketing has been neglected. According to Beni (2006), the travel and tourism sector underutilizes the brand concept in various sectors, and the "destination brand" can be a name, symbol, logo, or trademark that identifies and differentiates the destination from other competing destinations. Moreover, it conveys the promise of a memorable travel experience that is unique and associated with the destination (Beni, 2006). This idea underscores the relevance of this study to the image of Brazil.

According to Bignami (2002), strategic management of the image is a concept utilized in marketing for specific purposes to leverage product sales. Regardless of which tourist service is being addressed, the image of Brazil as a tourism destination needs to be coherent across the international tourism market because conceptual divergence in associations with the country's image can create uncertainty in the selection processes of foreigners who may be potential customers for the most varied destinations in Brazil.

\section{The Image of Brazil as a Tourism Destination}

Brazil is viewed as an exotic destination for foreigners in general, and the features that add to the country's brand include ecological diversity, a pleasant tropical climate, and friendly and cheerful people (Anholt, 2000). Such associations may be an important source of value for the Brazil brand in the tourism sector. Certainly, foreigners observe the attractive, positive features as well as the social problems and negative features. The two extremes observed and experienced by tourists directly cause immediate reflection on whether they are choosing a country as a vacation destination or as a tropical excursion. For Pérez-Nebra and Torres (2010), the destination image construct summarizes the organized impressions of a place, that may be held by actual or potential tourists. This construct has changed from the 1970s to the present moment, suggesting the construct of beliefs and ideas, imparting a subjective characteristic, and defined by the sum of beliefs, ideas, and impressions that a person has of a destination. 
On the one hand, the image of Brazil is viewed positively because of features such as Carnival, natural beauty, football, and music or people such as Pele, Gisele Bündchen, Ronaldo, and Zico. On the other hand, Brazil's image includes negative attributes, such as crime, violence, environmental degradation, hunger, and poverty (Kotler \& Gertner, 2004). Such images are varied and uneven, which may confuse foreigners and thus induce uncertainty when they are related to the image of Brazil.

The realistic yet controversial view of Bignami (2002) on the image of tourism in Brazil is bothersome, as indicated in the preface to her book, in which she writes that "stirring the hornets' nest spurs reflection" when addressing pre-conceived ideas about Brazil from abroad. The concept of the tourism experience is shown as a product and/or a service and has tangible and intangible characteristics: the destination of a tour package or the journey itself is intangible, and its features or structures, whether hotels, food, transportation, weather, or the population, are tangible. According to Bignami (2002), the image changes in time and space. The image, although it is a variable that influences tourist flows in Brazil, has both of these characteristics and can be changed. Nevertheless, an idealized image without well-defined structural and social bases is worth nothing (Bignami, 2002).

As a positive archetype, a survey by the Economic Research Institute Foundation (FundaçãoInstituto de PesquisasEconômicas - FIPE) and the Brazilian Tourist Board (Embratur) conducted in 2004 and 2005 pointed to "the hospitality and the taste for Brazil" as the most favorable motive for travelling to the country. That study also revealed that the Brazilian people, not their habitat, explain the enchantment of foreigners travelling to Brazil. Thus, the friendliness of the Brazilian people is one of the most significant competitive advantages of the Brazilian tourism industry in the international market (Oliveira \& Martins, 2009).

Certain countries attract large numbers of foreign tourists as an excellent opportunity to promote their image, products, and services (Jaffe \& Nebenzahl, 2001), favoring their strengths, which is a model that Brazil could exploit to develop its marketing actions for strategies to spread its image. However, considering the negative image of Brazil abroad, this is a country that is remembered as a scene of violence by the media and, therefore, as an unsafe location for tourists (Pérez-Nebra \& Rosa, 2008), which is a known fact that confirms the need to ground the image of Brazil in international tourism.

Because the concerns about the growth and development of tourism are numerous, whether in private-sector companies, governmental institutions of the public sector, or tourism institutions and agencies, establishing goals and directing the development of the sector through a national tourism policy are options for guiding strategies (Gee \& Fayos-Solá, 2003). The requirements of such strategies would vary according to the type of activity and the attractiveness and local culture of each destination, which would be related to aspects of the Brazilian image. The coordinated efforts between the government and industry can explain the value of tourism because such efforts are more comprehensive and less sensational than those of the media; this value is both economic and socio-environmental (Gee \& Fayos-Solá, 2003). Another aspect pointed out by Kastenholz (2010, p.315) is that "images are both individual and socially shaped and shared mental constructs", conceivably, making the Brazil image concept related to both cultural elements and media associations known publicly.

Bignami (2002) claims that the image of Brazil is strongly portrayed through negative associations of the country related to cultural aspects, and this evidence need not be present in the promotion of Brazil nor be viewed as a lack of effective action from the public sector. The solution would include a review of the valuation of national culture as a whole and in all instances should be enhanced by a comprehensive policy for tourism in Brazil.

According to Morgan et al. (2010), academia has yet to explore the relationship between a country's culture and image management, given that different cultural attributes impose a sense of unity in a place. A similar position was taken by Giraldi, Giraldi and Scaduto (2011) in discussing Brazil's image through the theory of social representation. Because of the perception and projection of the country's image abroad, the authors identified five categories (population, politics, nature, sports and economy) that were considered in the process of defining the country's image.

Meanwhile, any positive image promotes a destination, based on the assumption that "tourism destinations need to provide favorable experiences to tourists, in which they will create a positive image and recommend the place to others in turn helping potential tourists develop a favorable image that affects the destination choice" (Qu et al., 2011, p.473).

It is believed that the solution may be found in progressive innovative planning in the tourism industry, whether public or private, as well as in ongoing development in the management of the "Brazil brand" used for promoting tourism in the country. In this way, positioning strategies may be focused on poor, distorted, poorly formed, or incomplete images. For example, studies on changing the image of a country showed that achieving this goal is a long-term process that can 
be related to infrastructure problems, thus requiring cooperation among the sectors, associations, and services involved.

Finally, Kastenholz (2010, p.315) indicates that "destination images should correspondingly be dependent on the frequently country-specific image-projection [...] both via direct destination-marketing efforts and through the respective commercialization channels (tour operators, travel agencies)".

\section{Empirical Research}

Both the type of field research and the nature of the method were qualitative and exploratory. The primary data used were collected through in-depth interviews to explore the content found in the real context of the sample (Hair et al., 2011).

Three types of respondents composed the sample: (i) professionals from twenty travel agencies in the United States (US) and (ii) three experts in international tourism. The interviewees were located in the cities of New York, Miami, Orlando, and Atlanta. In total, there were twenty-three respondents, a number considered to be adequate for exploratory research. The number suggested by Hair et al. (2011) is 1 to 50 .

The instrument used as a basis for personal communication during interviews was a script in the native language of the interviewee. The interviews were conducted during the months of July and August 2011 in person at the workplaces of the interviewees.

To assess the content of the collected data, the conceptual model and the associated steps of Bardin (2010), Flick (2009), and Hair et al. (2011) were used. Thus, after transcribing the interviews and taking notes, the responses were categorized according to the theoretical model being investigated and then analyzed, compared, and explored. The analysis structure for the interpretation of the transcribed text was based on the following steps: (i) relating the theoretical frameworks to their respective concepts in the context of the research theme, (ii) counting the similarities and differences in the respondents' answers, and (iii) citing relevant passages in full, as verbalized by the respondents.

\section{Presentation and Analysis of Results}

The image of Brazil, as discussed in the literature review, is ambiguous, as highlighted in studies by Anholt (2000) and Bignami (2002), and sparse with respect to in-depth academic studies conducted abroad, characterizing it as a research field yet to be explored. In the present study, statements addressing the image of Brazil converged on diversity and ambiguity, as quoted by most authors in the literature reviewed, namely, Anholt (2007); Bignami (2002); Giraldi et al. (2011); Morgan et al. (2010); Nadeau et al. (2008); Pérez-Nebra and Torres (2010); and also Pike (2008). The fact that Brazil has both positive (natural beauty, hospitality) and negative (violence, poverty, environmental degradation) elements directly affects how the image of the country is formed through a holistic process (Tapachai \& Waryszak, 2000).

One of the experts interviewed, identified as E1, commented on the image of Brazil, which is still distorted in the United States:

This type of image needs to be more developed [...] Because you hear a lot about this folklore thing of being a happy, content, Carnival people. The image of Carnival remains very firm in the minds of Americans. In my view, the image is wrong; the country has been seen as the country of Carnival and was characterized as the country of mulatto women, of Carmen Miranda, since that time.

Another expert interviewed (E2) described his image of Brazil before coming to the country as follows:

In 2003, I thought it would be like Mexico or Chile. I knew of the growing economy, that the language was Portuguese; I had the idea of a magical country, but did not know how. I knew the country for its Brazilian music, the Amazon, and its beaches. I knew that somehow the country was different and exotic. I came to live in Brazil for the New York Times in 2004. In two years, I traveled the country and saw that it is more diverse than what people say. You need to choose the part of Brazil to visit and the type of experience. The diversity is great, and the country is culturally self-sufficient. There are places quite different from each other. And I think it's the most bureaucratic country in Latin America to live in.

In contrast, according to another expert interviewed (E3), North American tourists visiting Brazil are uncertain about safety before arriving and, upon return, are in love with the country. This observation was confirmed by the responses in the study's sample, as shown below.

Similarly, agencies in the United States stated their opinions and perceptions regarding the images they believe their North American clients held of Brazil before and after their travel to a Brazilian destination. The responses were 
considered by categorizing them and counting the frequency and similarity of terms taken from the full content extracted from the question, "What is the image of Brazil that American tourists have before and after the trip?"

A total of twenty negative citations and thirty positive citations were observed before the trip, in which the negative aspects mentioned by most were fear, insecurity and violence, and unknown expectations. As for the positive images before the trip, the majority of statements considered Brazil to be a cheerful country with happy people, followed by the terms "party, fantasy, and fun", "natural beauty and lively destinations, the exotic, and vibrant", and "good and positive image". Among the aspects observed in statements made after the trip, there were nine negative aspects and fourteen positive aspects. The most cited negative aspects were violence, followed by the comment, "not satisfied with the accommodations/hotel, and lacking quality". The positive aspects of the image held after the trip by the majority of respondents were "satisfied", followed by "nice people".

Several references of the respondents corroborate the examples given by Kotler and Gertner (2004) in which the positive image of Brazil is epitomized by Carnival, natural beauty, football, and music or by people such as Pelé, Gisele Bündchen, Ronaldo, and Zico. The negative image is represented by crime, violence, environmental degradation, hunger, and misery. Such discrepancies in positive and negative images may confound the choices of foreigners, thereby causing uncertainty in how they relate to the tourism experience.

Figures 1 and 2 show those aspects previously cited regarding the image of Brazil before and after the trip, with the respective number of themes grouped within each category. The studies on country of origin by Jaffe and Nebenzahl (2001) explain that the evaluation and judgments by a consumer of a particular country's product or brand and their respective characteristics, in the case of Brazil, occur by considering new product categories, as demonstrated through the positive or negative images of Brazil described by the interviewees. For example, interest or lack of interest in gaining familiarity with the country may occur, depending on whether one views images of "exotic destination" or "drug trafficking", respectively.

In considering Bignami's (2002) claim that the strategic management of an image to leverage product sales can be applied to the tourism market for selling travel packages to Brazilian destinations, one may assume that the image is the first consideration in the purchasing decision of a tourist. However, it is important to review the negative and positive aspects of images that tourists held before and after visiting Brazil, as discussed in this study, to minimize the unfavorable aspects and highlight the attractive ones. Therefore, the planning and execution of marketing activities in the management of Brazil's image can be strategically conducted for tourism as well as for other sectors.

\section{Concluding Remarks}

This article has evaluated the image of Brazil as a tourism destination based on the existing literature with additional references from US travel agents and tourism experts. The travel agencies play an important role in the United States as sales channels, because Brazil country image is considered confused and dichotomic not only in the U.S. market, but also internationally. Additionally, its exotic and unknown reputation consist of lack of enough information in order to tourists decide travelling to Brazil. In this way, when U.S. tourists decide to visit Brazil, they request a specialist in tourism or in Brazilian destinations.

Based on that, this investigation found that the image of Brazil is still puzzled and not solid and resistant. A disparity was found in associations of Brazil's image in various contexts from the destination image characteristics. As shown in the literature review and supported by field research, the image for a tourism destination cannot be developed simply through promotional campaigns and esthetically appealing logos; prior to these efforts, the image is shaped by a broad set of factors or based on a holistic process.

Therefore, it can be concluded from the present study that the image of Brazil is not fixed; rather, it has the potential to evolve and thereby may contribute effectively to the ability of Brazil to draw international tourism as well as foreign investment. However, to enable a strategic effort, more studies are needed of specific markets to capture the interest in purchasing Brazilian products and services due the image of a tourism destination, which is formed by associations with Brazil. By contrast, negative associations with a country may hinder consumer choice. It is believed that to improve the marketing of the image of Brazil, the development of a strategic plan with a communications program aimed at promoting international tourism would be legitimate.

Additionally, by the same token, Kastenholz's (2010) research findings state that in order to overcome the tourists' feelings of strangeness about a destination, an effort in improving communication and information at the destination site should be arranged. The author also insists that in addition to a careful analysis of the consequences of opting for specific segments, in a holistic planning approach could further help destinations to develop in a more successful and sustainable way by actively managing demand. 
By addressing this topic, we hope to contribute to future research to advance the development of the image of Brazil and the position of the country in global tourism and also other sectors of the Brazilian economy that grow considerably in times of international crises.

The main limitation of this study pertains to the lack of interviews conducted directly with US customers through the agencies surveyed, which could generate direct information from the end of the communication channel for significant analysis. One should also consider the very exploratory nature of the study, which, despite not supporting generalizations, can still provide consistent evidence from direct field research with tourists from other countries and/or regions who have either visited or have never been to Brazil.

\section{References}

Anholt, S. (2000). The nation as a brand. Across the Board, 37(10), 22-27.

Anholt, S. (2007). Competitive identity: The new brand management for nations, cities and regions. New York: Palgrave Macmillan.

Baloglu, S., \& McCleary, K. W. (1999). A model of destination image formation. Annals of Tourism Research, 26, 868-897.

Bardin, L. (2010). Análise de conteúdo [Content analysis]. Lisboa: Edições 70.

Beni, M. C. (2006). Política e planejamento de turismo no Brasil [Tourismpolicyandplanning in Brazil]. São Paulo: Aleph.

Bignami, R. (2002). A imagem do Brasil no turismo [Brazil'simage in tourism] (2nd ed.). São Paulo: Aleph.

Cioffi, S. (2011). Turismo de fronteira e fronteiras da mediocridade [Frontiertourismandthefrontiersofmediocrity].

Folha.com. Blogs da Folha. [Online] Available:

http://blogdoturismo.folha.blog.uol.com.br/arch2011-09-11_2011-09-17.html (September 12, 2011)

Ekinci, Y., \& Hosany, S. (2006). Destination personality: An application of brand personality to tourism destinations. Journal of Travel Research, 45, 127-139. http://dx.doi.org/10.1177/0047287506291603

Flick, U. (2009). Introdução à pesquisaqualitativa [Introduction to qualitative research] (3th ed.). Porto Alegre: Bookman.

Gallarza, M. G., Saura, I. G., \& Garcia, H. C. (2002). Destination image: Towards a conceptual framework. Annals of Tourism Research, 29, 56-78. http://dx.doi.org/10.1016/S0160-7383(01)00031-7

Gee, C. Y., \& Fayos-Solá, E. (Orgs.). (2003). Turismointernacional: Uma perspectiva global [International tourism: A global perspective] (2nd ed.). Porto Alegre: Bookman.

Giraldi, J. M. E., Giraldi, I. M. E., \& Scaduto, A. A. (2011). Brazil's image as a social representation process. African Journal of Business Management, 5, 8821-8831. http://dx.doi.org/10.5897/AJBM10.1510

Hair, J.F., Celsi, M.W., Money, A.H., Samouel, P., \& Page, M.J. (2011). Essentials of business research methods. New York: M. E. Sharpe.

Jaffe, E. D., \& Nebenzahl, I. D. (2001). National image \& competitive advantage. Copenhagen: Copenhagen Business School Press.

Kastenholz, E. (2010). Cultural proximity' as a determinant of destination image. Journal of Vacation Marketing, 16, 313-322. http://dx.doi.org/10.1177/1356766710380883

Kotler, P., \& Gertner, D. (2004). O estratégico marketing de lugares [The strategy of marketing places]. Dossiê HSM Management, 44, 62-93.

Machado, D. F. C., Medeiros, M. L., \& Gosling, M. (2010). Uma revisão teórico-metodológica da imagem de destinos na perspectiva do marketing turístico [A theoretical-methodologicalreviewoftheimageofdestinationsfrom a tourism marketing perspective] [Abstract]. In Seminário da Associação Nacional Pesquisa e Pós-Graduação em Turismo, 7. [Online] Available: http://eventos.univerciencia.org/turismo/index.php/seminanptur/2011/paper/view/648 (December 10, 2011)

Morgan, N., Pritchard, A., \& Pride, R. (2010). Destination branding: Creating the unique destination proposition. Oxford: Elsevier.

Nadeau, J., Heslop, L., O'Reilly, N., \& Luk, P. (2008). Destination in a country image context. Annals of Tourism Research, 35, 84-106. http://dx.doi.org/10.1016/j.annals.2007.06.012 
Oliveira, C. T. F., \& Martins, P. E. M. (2009). A hospitalidade e cordialidade brasileira: O Brasil percebido por estrangeiros [Brazilianhospitalityandcordiality: ...]. Turismo em Análise, 20, 196-209.

Qu, H., Kim, L. H., \& Im, H. H. (2011). A model of destination branding: Integrating the concepts of the branding and destination image. Tourism Management, 32, 465-476.http://dx.doi.org/10.1016/j.tourman.2010.03.014

Pérez-Nebra, A. R., \& Rosa, C. J. (2008). As novas estratégias de promoção do Brasil no exterior: Estudo de caso [New strategies for promotingBrazilabroad: A case study]. Turismo em Análise, 19, 450-471.

Pérez-Nebra, A. R., \& Torres, C. V. (2010). Medindo a imagem do destino turístico: uma pesquisa baseada na teoria de resposta ao item [MeasuringtheTourismDestinationImage: a SurveyBasedonthe Item Response Theory]. RAC, 14, 80-99.

Pike, S. (2002). Destination image analysis - a review of 142 papers from 1973-2000. Tourism Management, 23, 541-549. http://dx.doi.org/10.1016/S0261-5177(02)00005-5

Pike, S. (2008). Destination marketing: An integrated marketing communication approach. Oxford: Elsevier.

Roth, P. K., \& Diamantopoulos, A. (2008). Advancing the country image construct. Journal of Business Research, 62, 726-740. http://dx.doi.org/10.1016/j.jbusres.2008.05.014

Tapachai, N., \& Waryszak, R. (2000). An examination of the role of beneficial image in tourist destination selection. Journal of Travel Research, 39, 37-44. http://dx.doi.org/10.1177/004728750003900105

World Tourism Organization. (2012). Annual Report 2012. Geneva: Author. [Online] Available: http://www.wto.org/english/res_e/reser_e/annual_report_e.htm (February 15, 2012)

Table 1. Dimensions of the tourist destination image

\begin{tabular}{|l|l|}
\hline \multicolumn{1}{|c|}{ Dimensions Discussed } & \multicolumn{1}{c|}{ Author Considered } \\
\hline $\begin{array}{l}\text { People, products, governance, tourism, culture } \\
\text { and immigration and investment }\end{array}$ & Anholt, 2007 \\
\hline $\begin{array}{l}\text { Complexity, multidimensionality, dynamism, } \\
\text { measurability, plurality, and relativity }\end{array}$ & Machado et al., 2010 \\
\hline $\begin{array}{l}\text { Intangibility and risk, variability and } \\
\text { inseparability, perishability, substitutability }\end{array}$ & Pike, 2008 \\
\hline Perceptions such as images of the destination & Nadeau et al., 2008 \\
\hline $\begin{array}{l}\text { Associations of the country of origin and } \\
\text { information about the origin of products }\end{array}$ & Roth and Diamantopoulos, 2009 \\
\hline Lodging, transportation, food & Tapachai and Waryszak, 2000 \\
\hline
\end{tabular}

Source: Adapted by the authors. 


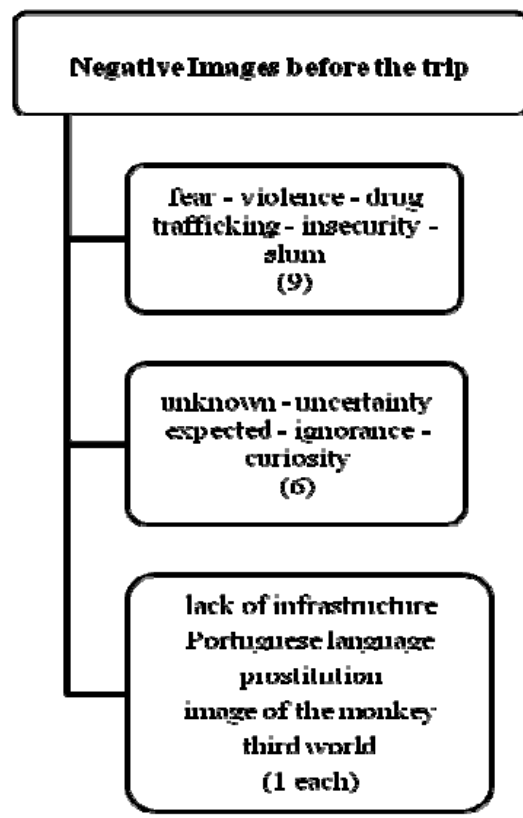

Positive fmages before the trip

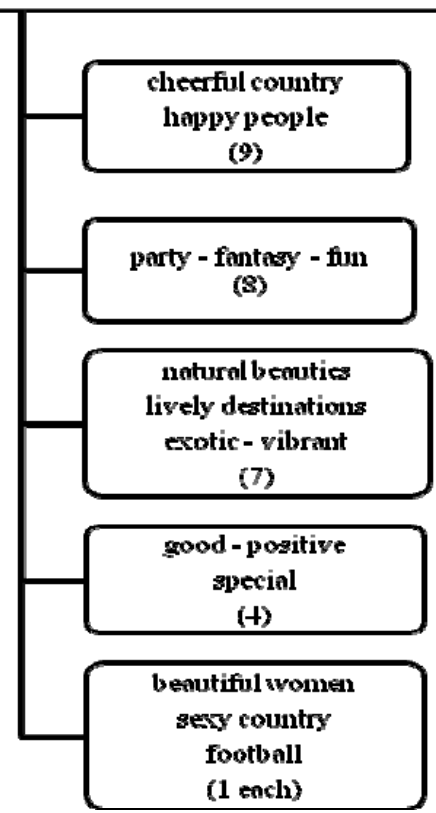

Figure 1. The image of Brazil before the trip

Source: Developed by the authors.
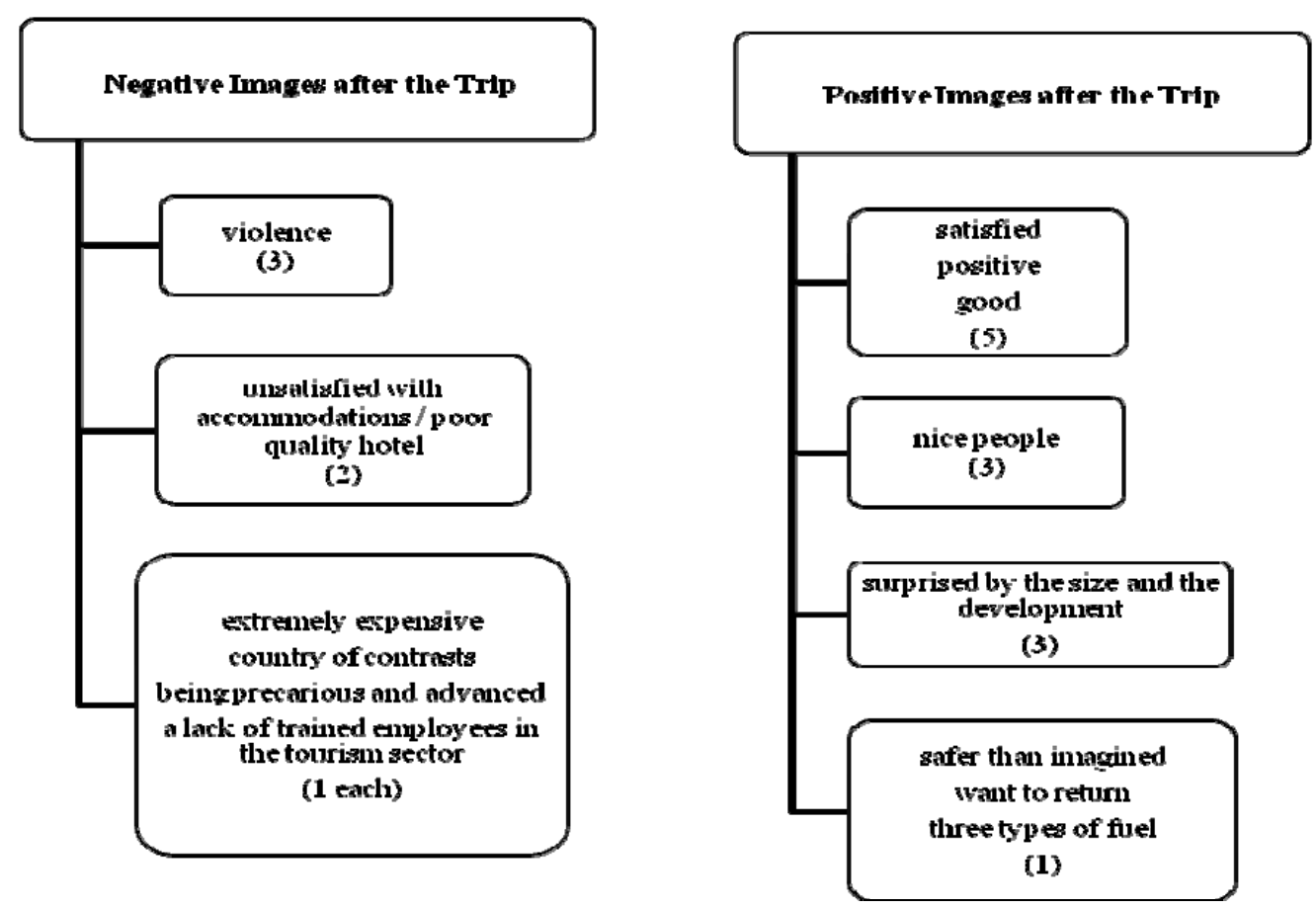

Figure 2. Images of Brazil after the trip

Source: Developed by the authors. 